\title{
ANNOUNCEMENTS
}

NOTE: if the links below are inactive, this most likely means that you are using an outdated version of Adobe Acrobat Reader. Please update your Acrobat Reader at adobe.com and try the links again.

\section{CALLS FOR PAPERS}

15 Sep 2007 Deadline

1 Oct 2007 Deadline

30 Nov 2007 Deadline

Dec 2007 Deadline
The 6th Annual Auditory Perception, Cognition, and Action Meeting (APCAM) will be held on Thursday, November 15, 2007 at the Hyatt Regency Hotel in Long Beach, California. Topics may include (but are certainly not limited to): Auditory localization, motion perception, and spatial cognition; auditory object, event, and pattern perception (including speech); aurally guided action and navigation; auditory scene analysis; auditory timing and attention; pitch, loudness, and timbre perception; music perception, cognition, and performance; comparative auditory processing; auditory behavioral neuroscience; and auditory memory and source identification. For on-line submission and registration, go to: http://www.apcam.us/, and for more information contact: Peter Q. Pfordresher (pqp@buffalo.edu ).

A two-day international conference, the Empirical Musicology Institute of Musical Research, will be held at the University of London on 2-3 April, 2008. Contributions are welcome from researchers at all levels and are especially encouraged from postgraduate students and researchers early in their careers. Abstracts for papers ( 200 words) and posters (100 words) may be sent to the Administrator, Institute of Musical Research (music@sas.ac.uk). Additional information is available at http://www.sempre.org.uk/conf 33.html .

The $4^{\text {th }}$ Conference on Interdisciplinary Musicology (CIM'08) will be held in Thessaloniki, Greece on July 2-6, 2008. Information on the conference is available at http://www-gewi.uni-graz.at/staff/parncutt/cim.htm; a "Call for Papers" PDF file may be downloaded from that web page.

The $10^{\text {th }}$ International Conference on Music Perception and Cognition (ICMPC10) will be held at the Center for Research and Development in Higher Education at Hokkaido University in Sapporo, Japan on August 25-28, 2008. The expected deadline for submission of proposals will be in December 2007 (exact date not yet available). The organizers have set up a conference blogsite at http://icmpc10.typepad.jp/. 


\section{CONFERENCES}

\author{
2007, July-August
}

2007, August

2007, September

2007, September

2007, November

2007, November

2007, December

2008, April
SMPC 2007, the biennial meeting of the Society for Music Perception and Cognition, will take place at Concordia University (Montreal, Quebec, Canada) from July 30 to August 3, 2007. Paper and poster proposals in the areas of music theory, psychology, psychophysics, linguistics, neurology, neurophysiology, ethology, ethnomusicology, artificial intelligence, computer technology, physics, and engineering will be offered. Additional information may be found at http://alcor.concordia.ca/ smpc2007/

The $3^{\text {rd }}$ Conference on Interdisciplinary Musicology (CIM07) will take place in Tallinn, Estonia from 15 to 19 August 2007. The theme of CIM07 is singing from the viewpoint of all musically and musicologically relevant disciplines. Visit the conference web site at http://www-gewi.uni-graz.at/cim07/index2.htm for further information.

The 8th International Conference on Music Information Retrieval (ISMIR 2007) will be held at the Vienna University of Technology in Vienna, Austria, from Sunday, September 23 to Thursday, September 27, 2007. The overall goal of this annual conference series is to provide a forum for those involved in accessing digital musical material, and topic areas of the conference include "Music Perception, Cognition, Affect, Emotions" and "Human-Computer Interaction and Interfaces." Additional information is available at http://ismir2007.ismir.net/cfp.html

Music-AL Workshop 2007, organized by the Interdisciplinary Centre for Computer Music Research, will convene on September 10, 2007 at the Belem Cultural Centre, in Lisbon, Portugal. Additional information is available at $\underline{\text { http://cmr.soc.plymouth.ac.uk/Musical2007/ }}$

International Symposium on Performance Science (ISPS), Porto, Portugal (see CALLS FOR PAPERS, above)..

6th Annual Auditory Perception, Cognition, and Action Meeting (APCAM), Long Beach, California (see CALLS FOR PAPERS, above)..

Inaugural International Conference on Music Communication Science (ICOMCS), 5-7 December, 2007, University of New South Wales, Sydney, Australia. Details can be found at the ICOMCS web site: http://marcs.uws.edu.au/links/ICoMusic. The conference will attract people from all walks of research and performance life, including musicologists, psychologists, educators, linguists, composers, engineers, computer scientists, speech scientists, physicists, philosophers and performance artists. The aim of the conference is to bring a wide range of presenters together, ranging from students to established researchers with an interest in finding or presenting synergies from several disciplines to help solve problems in music, or to use elements of music and music research to address problems in other disciplines.For more information contact Emery Schubert (E.Schubert@unsw.edu.au) or Kate Stevens (kj.stevens@uws.edu.au).

Empirical Musicology Institute of Musical Research, University of London (see CALLS FOR PAPERS, above). 
2008, July

2008, August
The $4^{\text {th }}$ Conference on Interdisciplinary Musicology (CIM'08), Thessaloniki, Greece (see CALLS FOR PAPERS, above).

$10^{\text {th }}$ International Conference on Music Perception and Cognition (ICMPC10), Hokkaido University, Sapporo, Japan (see CALLS FOR PAPERS, above).

Empirical Musicology Review welcomes announcements of national and international symposia, conferences, workshops, and other activities advancing empirical research in music. Please send announcements to editor@emusicology.org . 